Geografia e Ordenamento do Território, Revista Electrónica

Centro de Estudos de Geografia e Ordenamento do Território

http://cegot.org

ISSN :2182-1267

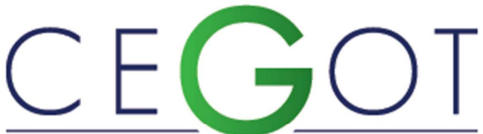

Centro de Estudos de Geografia e Ordenamento do Território
CÁSSIA, RITA DE

Universidade Federal do Rio Grande do

Norte/Centro de Ciências Humanas, Letras e

Artes/Departamento de Geografia

59086-005, L'acqua Condomínio Clube, Rua Lúcio Viveiros, n.

649, bloco I, apt 1502, Neópolis, Natal - RN, Brasil

ricassiacg@gmail.com

\title{
Políticas públicas no Nordeste do Brasil: a produção de enclaves e de desigualdades socioespaciais
}

Public Policies in the Brazilian northeast: the production of enclaves and inequalities social spatial

Referência: Cássia, Rita de (2015). Políticas públicas no Nordeste do Brasil: a produção de enclaves e de desigualdades socioespaciais. (GOT), n. 8 (dezembro). Centro de Estudos de Geografia e Ordenamento do Território, p. 11-31, dx.doi.org/10.17127/got/2015.8.002

\section{RESUMO}

O trabalho trata das políticas públicas no Nordeste do Brasil e sua relação com a produção de enclaves e de desigualdades socioespaciais no contexto regional. A política pública é relevante por ser um dos instrumentos importantes para o ordenamento territorial. Baseiase nas críticas aos enfoques espacialistas que atribuem uma autonomia própria à região, tanto no nível da prática quanto do planejamento, e afirmam que o critério alternativo é único para explicar os fenômenos espaciais considerando-os como manifestações do modelo e das necessidades nacionais e internacionais de acumulação de capital em diferentes conjunturas. Pensar o Nordeste e as políticas públicas requer considerá-lo a partir de sua inserção no sistema de acumulação, enquanto região periférica, buscando compreender os resultados dessa inserção no território e na sociedade.

Palavras-chave: Nordeste. Políticas Públicas. Desigualdades Socioespaciais. Estado

\section{ABSTRACT}

This article analyzes the public policies in Northeast Brazil and its relation with the production enclaves and socio-spatial inequalities in the regional context. Public policy is an important tools for regional planning. The article is based on the criticism of theoretical 
approaches who impute autonomy to the region, both in terms of practice and planning, and claim that the alternative criterion is only to explain the spatial phenomena considering them as a model of demonstrations and needs domestic and international capital accumulation in different situations. Thinking public policies in the Northeast requires consider them from their inclusion in the accumulation system, while peripheral region and therefore understand their results in the context of territory and society.

Keywords: Northeast. Public Policy. Socio-spatial inequalities. State.

\section{Introdução}

O Nordeste brasileiro, ao longo da história do desenvolvimento socioeconômico do Brasil, tem sido objeto de diversos estudos e análises, nas mais variadas áreas do conhecimento. Sendo assim, muitas questões sobre essa região já foram devidamente esclarecidas, enquanto outras ainda são merecedoras de esforços no sentido de melhor compreendê-las, e assim contribuir para que soluções e/ou alternativas de soluções possam ser evidenciadas. É com esse objetivo que estamos nos propondo a discutir as políticas públicas implementadas pós a criação da Superintendência do Desenvolvimento do Nordeste (SUDENE), com vistas ao desenvolvimento regional, considerando que tais políticas propiciaram, de um lado, a formação de enclaves econômicos, os quais favoreceram a inserção da região Nordeste no processo de reprodução ampliada do capital via processo de industrialização; e de outro, a produção de profundas desigualdades socioespaciais.

Sendo assim, tomamos como pressuposto a ideia de qua as políticas públicas implementadas pelo Estado brasileiro após a criação da Superintendência do Desenvolvimento do Nordeste - SUDENE, com o objetivo de promover o desenvolvimento regional via processo de industrialização, ao dinamizarem a economia, contribuiram significativamente para a formação de enclaves, constituídos de áreas dinâmicas, no dizer de Araujo (2000); ou espaços luminosos, no dizer de Santos (1996), ao mesmo tempo em que não apenas aprofundaram as desigualdades socioespaciais até então existentes, mas também criaram novas desigualdades, reafirmando, desse modo, o caráter contraditório do desenvolvimento capitalista, o qual, na sua essência, é desigual e combinado.

A leitura que fazemos das políticas públicas direcionadas para a região Nordeste do Brasil é tributária da crítica feita aos enfoques espacialistas, que compreendem os processos 
regionais como resultantes da autonomia inerente à própria região. Assim, o entendimento exposto toma como caminho para a explicação dos fenômenos espaciais o modelo de acumulação do capital, seja nacional ou internacional segundo as diversas conjunturas de sua reprodução.

Desse modo, torna-se necessário considerar o caráter das relações internacionais; e, sobretudo, o dado real inerente à situação de dependência dos países latino-americanos no contexto mundial. Ou seja, pensar as políticas públicas no Nordeste brasileiro requer, de certo modo, considerá-las a partir de sua inserção no sistema das demandas nacionais e internacionais de acumulação, enquanto região periférica.

O Nordeste ao qual vamos nos referir é o Nordeste que nasce com o novo nacionalismo, baseado na criação de cinco regiões - Norte, Nordeste, Sudeste, Sul e Centro-Oeste - e valorização das diferenças geoeconômicas e socioculturais instituídas pelo Estado Novo, como espaço territorial que tem data de nascimento; mas também, é o Nordeste que ganhou identidade com a obra de Gilberto Freyre, ao discutir as relações sociais existentes na sociedade escravista; de Manoel Correia de Andrade, "A terra e o Homem no Nordeste"; e de Durval Munis, quando tratou da reinvenção do Nordeste. É ainda o Nordeste de uma geração de romancistas, como: José Lins do Rêgo, que retratou o Nordeste da cana de açúcar, e também do sertão; Rachel de Queiroz, que com sua obra "O Quinze", colocou em debate um dos mais discutidos temas relativo à região Nordeste: a seca; Graciliano Ramos, que também falou da seca nordestina em seu clássico livro: Vidas Secas; e de tantos outros brasileiros que descreveram, em tom realista, as condições de vida e os impasses da sociedade, seja aquela ralidade que se reproduzia no litoral, no contexto da cana de açúcar, demarcado pelo engenho, casa grande e senzala; seja aquela que vivia a realidade da seca no sertão, também com demarcações bem definidas, expressas pela relação latifúndio versus minifúndio.

A opção de Nordeste retratada acima se apoia no fato de que é esse Nordeste múltiplo que merece ser compreendido, dado o fato de que a seca, o cangaço, o messianismo e as lutas entre famílias fazem parte do imaginário que fundamentou as obras de denúncia, que desde os anos da década de 1930, abordam a referida região, embora fazendo parte de um mundo 
aparentemente decadente, ainda se fazem presentes por meio das relações sociais marcadas por desigualdes sociais e riqueza.

Essa imagem de um mundo violento e cruel se fez presente, por exemplo, nos filmes 0 cangaceiro, de Lima Barreto (1953); O pagador de promessas, de Anselmo Duarte (1960), baseado na peça de Dias Gomes, que conquistou a Palma de Ouro, em Cannes, em 1962; e Vidas Secas, de Nelson Pereira dos Santos (1963), baseado no livro de Graciliano Ramos.

Tanto em uma quanto na outra concepção, a ideia de Nordeste foi sendo construída sob a marca da seca, considerada como a causa maior da problemática social vivenciada pela população dessa região; e, portanto, explicação da pobreza absoluta da maioria da população. É por meio dessa ideia de que o Nordeste passa a ser percebido no contexto nacional como o lugar do atraso, do rural e do passado que resiste às mudanças, contrapondo-se à imagem construída a respeito da região Sudeste; isto é, a região do progresso, da indústria e do futuro.

Combater as secas e seus efeitos se configurou então como objetivo maior. A cada seca que ocorria, mais evidente ficava a pobreza da região Nordeste, pois a forte migração, acompanhada da mendicância, alastrava-se em todo o espaço regional. E assim, os nordestinos se tornaram os principais agentes na construção de Brasília, do mesmo modo que foram importantes, enquanto força de trabalho no processo de industrialização promovido pelo governo de Juscelino Kubitschek (JK), norteado pelo slogan, "cinquenta anos em cinco". Foram os nordestinos os principais construtores da cidade de São Paulo, que já na década de 1970 foi considerada a maior cidade da América Latina, bem como a mais industrializada.

Na obra "Geografia da Fome", publicada em 1952, o médico Josué de Castro fez um alerta para as autoridades governamentais sobre a problemática social e econômica emergente, como resultante da pobreza e da desigualdade social, apresentando a fome como a problemática social mais preocupante. Esse alerta, e mais os diversos estudos sobre a realidade nordestina, dentre eles, o relatório do trabalho desenvolvido pelo Grupo de Trabalho para o Desenvolvimento do Nordeste (GTDN) foram basilares para a discussão e levantamento da questão regional, sugerindo o Nordeste como uma região problema, de cujo entendimento emergiu o grande projeto político econômico capitaneado pelo 
economista Celso Furtado, que por meio de suas ideias, levou o Nordeste a ganhar relevância enquanto objeto de uma política pública específica enquanto região, simbolizada na criação da SUDENE. Era uma decisão importante no contexto da política de ordenamento territorial, que embora não explicitada, procurava ordenar o território para que o Nordeste fizesse parte do processo de expansão econômica capitalista.

Essas considerações sobre a ideia de Nordeste nos conduzem à compreensão de região segundo Oliveira, ao afirmar ser essa

(...) um espaço onde se imbricam dialeticamente uma forma especial de reprodução do capital e, por consequência uma forma especial de luta de classe, onde o econômico e o político se fusionam e assumem uma forma especial de aparecer no produto social e nos pressupostos da reposição. (OLIVEIRA, 1981, p29)

A busca incessante desse espaço para a reprodução do capital pode ser apontada como um vetor da participação efetiva do Estado por meio de políticas públicas, as quais têm sido vistas como de fundamental importância para resolução dos problemas inerentes à região Nordeste. Mas também, como um dos vetores da reprodução da realidade socioespacial ainda hoje existente.

\section{O Nordeste e as políticas públicas}

Para descortinar a trajetória de atuação do Estado brasileiro na região do Nordeste, inclusive sob a perspectiva da seca, o ponto de partida foi o período imperial. Nesse período, as secas já se apresentaram como um fenômeno devastador e provocador de problemas sociais. Daí, o surgimento da política das águas, vista como pouco eficaz, já que, na realidade, a sua maior contribuição, em especial, nos primeiros anos após a sua criação, foi o favorecimento e a reprodução dos coronéis, que implantaram, sob a sua ordem, formas de domínios que até hoje perduram na política regional, mesmo que se apresentem sob nova aparência e tenham uma escala de abrangência menor. Foram essas formas de domínios, associadas a outras práticas sociais, como o paternalismo e a estrutura oligarca, responsáveis pelo atraso ao qual foi submetida a região Nordeste em toda a sua história. 
A política das águas, que perdura ainda hoje - 2015 - tornou-se uma das políticas mais marcantes para o surgimento de um sujeito emblemático no cenário político e social nordestino: o coronel; e com ele, o coronelismo, que segundo Leal $(1975$, p. 252) constitui "um sistema político (...) dominado por uma relação de compromisso entre o poder privado decadente e o poder público fortalecido".

Durante o governo de Vargas (1930 - 1945) mudanças significativas ocorreram, ainda que sem promover transformações radicais, seja do ponto de vista político, seja do ponto de vista social. Tais mudanças se refletiram na passagem de um Estado autoritário, passivo, para um Estado autoritário, ativo.

No contexto do governo Vargas, a seca foi então diagnosticada como o principal e mais grave problema da região Nordeste, sendo a sua solução vista algo emergencial. Para tal, a compreensão que prevalecia era a de que, por meio de uma ação sistematizada, o Estado deveria implementar ações voltadas para os setores específicos da sociedade, buscando a promoção do desenvolvimento. Sob essa direção política é que foi criado, em 1945, o Departamento Nacional de Obras Contra as Secas (DNOCS), substituindo a Inspetoria Federal de Obras Contra as Secas (IFOCS).

Também no governo Vargas, deu-se a criação do Instituto do Açúcar e do Álcool (IAA), em 1933, que tinha por objetivos incentivar o consumo e regular o mercado de açúcar e álcool. Esse feito por meio da implantação de cotas de produção, limitando a produção da usina a uma quantidade máxima $60 \%$ de toda a cana em suas próprias terras, devendo o restante ser fornecido por produtores independentes.

Embora o marco da política regional de combate às secas no Nordeste tenha se manifestado desde o início do século XX, quando foi criada, em 1909, a Inspetoria de Obras Contra as Secas (IOCS), transformada, em 1919, em Inspetoria Federal de Obras Contra as Secas (IFOCS), foi a criação da SUDENE que passou a fomentar uma política de industrialização, como resposta ao diagnóstico efetuado pelo Grupo de Trabalho para o Desenvolvimento do Nordeste (GTDN), divulgado por meio de documento institucional intitulado GTDN, segundo o qual o desenvolvimento industrial seria a única forma de combater a miséria no Nordeste, e colocar essa região rumo ao desenvolvimento. Assim compreendendo, apresentava-se como meta fundamental promover o crescimento do setor industrial. 
Desse modo, a SUDENE, inserida no projeto amplo de desenvolvimento brasileiro, foi tomada como o principal instrumento para o exercício dessa política em busca da modernização dos processos produtivos e sociais, daí o duplo objetivo: econômico e social local; e o outro, associado ao compartilhamento dos imperativos globais da acumulação de capital, com suas necessidades de legitimação.

As políticas então implementadas, focalizadas no desenvolvimento da indústria, promoveu mudanças significativas no contexto espacial da região Nordeste, como a passagem do mundo rural para o mundo urbano industrial, com profundas repercussões em vários aspectos da vida do país. A evidência dessa realidade se expressa pelo acelerado processo de urbanização que ocorreu Nordeste como pode ser visto por meio dos dados da tabela 01.

\begin{tabular}{c|c|c|c|c|c|c}
\hline $\begin{array}{c}\text { REGIÃO } \\
\text { NORDESTE }\end{array}$ & 1960 & 1970 & 1980 & 1991 & 2000 & 2010 \\
\hline $\begin{array}{l}\text { POPULAÇÃO } \\
\text { URBANA }\end{array}$ & 7.680 .681 & 11980.937 & 17.959 .640 & 25.753 .355 & 32.929 .246 & 38.821 .246 \\
\hline $\begin{array}{l}\text { POPULAÇÃO } \\
\text { RURAL }\end{array}$ & 14.748 .192 & 16.694 .173 & 17.459 .516 & 16.716 .870 & 14.763 .395 & 14.260 .704 \\
\hline
\end{tabular}

Tabela 01 - Evolução da população urbana e rural do nordeste brasileiro 1960 - 2010

Fonte: Instituto Brasileiro de Geografia e Estatística (IBGE), Censo Demográfico: 1960; 1970; 1980; $1991 ; 2000$ e 2000.

Fazendo a leitura dos dados da tabela, podemos perceber o crescimento da população urbana e a diminuição da população rural. Esse crescimento ainda se torna mais explícito quando o expressamos em números percentuais. Segundo os dados apresentados, em 1960, o Nordeste do Brasil possuía apenas 34,24 \% de sua população na zona urbana; e em 2010, o percentual aumentou para $72,12 \%$.

Essa nova realidade foi favorável ao crescimento econômico, bem como à expansão de cidades, fato que ocorreu de forma rápida, porém, bastante desordenada. 0 crescimento da cidade, motivado pelo expressivo movimento da população rural para a zona urbana propiciou o crescimento urbano de cidades nordestinas, como Sobral, no Ceará. Caicó e Mossoro, no Rio Grande do Norte (RN); Campina Grande, na Paraiba; Caruaru, em 
Pernambuco (PE); além de outras, as quais se constituem em importantes centros urbanos do Nordeste, os quais desempenham funções urbanas importants, além de se apresentarem como espaços econômicos importantes, graças ao mercado consumidor que cada um representa na economia regional.

Esse crescimento se deu graças às políticas desenvolvidas pelo Estado, as quais permitiram à região Nordeste acompanhar o intenso processo de "modernização" política e econômica que ocorria em todo o território brasileiro. No entanto, assim como os demais processos que ocorrem no contexto da sociedade capitalista em prol da reprodução do capital, as contradições também se fizeram presentes, daí resultando áreas com dinamismos econômicos e sociais totalmente diferenciados.

\section{Política pública no Nordeste e suas contradições}

A seca no Nordeste foi uma referência para a formulação de políticas públicas territoriais e específicas, uma vez que o fenômeno foi apontado como o principal vetor dos problemas que ocorriam na referida região; e, desse modo a causa maior das desigualdades sociais e espaciais existentes, seja no âmbito intrarregional, seja no âmbito nacional. Assim compreendida, resolver a problemática da seca seria resolver os problemas do Nordeste. Mas, como resolver o problema da seca?

Solucionar o problema da seca sempre se apresentava como a resposta mais factível. Por isso, as políticas implementadas para o Nordeste seguiam essa direção. E assim, surgiu um dos órgãos mais emblemáticos da política das águas: o Departamento Nacional de Obras contra as Secas (DNOCS).

A criação do DNOCS, em 1945, em nada mudou a intervenção do Estado, feita até então sob a tutela do IOCS, e depois da IFOCS. Porém, o DNOCS promoveu o fortalecimento da estrutura produtiva e social, baseada tanto no latifúndio quanto no minifúndio, que reproduziu as economias algodoeira e pecuária, propiciando as condições favoráveis à captura do Estado pelo poder oligárquico vigente, como assinala Oliveira (1981). 
A Política do DNOCS, sem fugir daquela já efetuada pela IFOCS, era voltada para a construção de barragens, perfuração de poços, construção de estradas e elaboração de estudos ecológicos: a ecologia, a geologia, a pedologia, a hidrologia e a botânica. O uso da irrigação, uma das saídas apontadas por vários estudiosos, não parecia ser um dos objetivos marcantes desse órgão, fato que pode ser constatado por meio da localização de importantes reservatórios de água construídos pelo DNOCS, que não permitiram tal prática. É o caso do açude Cedro, no Estado do Ceará; da barragem de Coremas, na Paraíba; e do açude de Gargalheiras, no Rio Grande do Norte. Assim, após 50 anos da criação do DNOCS, a área irrigada no Nordeste não ultrapassava 5.000 hectares (ha).

Na realidade, o que podemos afirmar é que esse órgão reforçou a estrutura arcaica, baseada no coronelismo, e expandiu a pecuária dos grandes e médios fazendeiros, além de contribuir para reforçar a existência de um fundo de acumulação, típico da acumulação primitiva. No cerne dessa estrutura arcaica, estavam moradores, meeiros, parceiros e pequenos sitiantes, produzindo culturas alimentares para a subsistência, ao mesmo tempo em que se tornavam mão de obra barata a ser recrutada para a construção de açudes e benfeitorias nas grandes propriedades, tornando-se também um dos pilares da política exercida pelos coronéis e oligarcas que se reproduziam no poder.

Assim, a política pública advinda com a criação do DNOCS em nada modificou a estrutura política e econômica do Nordeste brasileiro. Ao contrário, tornou essa política mais forte, de modo que após a Segunda Guerra Mundial, quando novas estruturas econômicas mundiais começaram a se consolidar, tendo os Estados Unidos à frente do processo de expansão e reprodução do capital, novas demandas socioterritoriais passaram a ser efetivadas. 0 sistema coronelístico então existente não respondia satisfatoriamente a essas demandas. Era preciso que mudanças fossem efetivadas. Surgiram então políticas públicas de caráter desenvolvimentista.

Para a promoção do desenvolvimento industrial no âmbito regional fazia-se necessário que políticas de infraestrutura fossem efetivadas com a maior brevidade possível. Daí, a criação da Companhia Hidrelétrica do Vale do São Francisco (CHESF); e da Companhia do Vale do São Francisco (CVSF), criada em 30 de agosto de 1948. Caberia à CVSF o desenvolvimento do Vale do Rio São Francisco, assim como ao Banco do Nordeste do Brasil (BNB), que assumiria 
a função de agente catalisador do desenvolvimento do Nordeste, integrando-o à dinâmica da economia nacional. A centralização de toda essa política ficou a cargo da SUDENE, criada sob Lei no 3.692, de 15 de dezembro de 1959, assinada pelo então Presidente da República, Juscelino Kubistchek.

Criada em um contexto de descontentamento com as ações do IAA e do DNOCS, a SUDENE, enquanto forma de intervenção do Estado no Nordeste, tinha como objetivo principal promover e coordenar o desenvolvimento da região Nordeste, objetivo esse apontado pelo GTDN como fundamental para responder à crise social que tinha sua origem na estrutura de produção vigente e no subdesenvolvimento da própria região, sendo a promoção do desenvolvimento industrial a principal ação a ser desenvolvida.

Para atingir esse objetivo, diversos programas, projetos e políticas públicas foram então efetivados, todos direcionados à promoção do desenvolvimento do Nordeste. Na essência, a função maior da SUDENE era mudar a realidade social do Nordeste. Isto é, criar as condições favoráveis a práticas vinculados ao pensamento urbano industrial, e assim contribuir e fazer parte efetiva do processo de acumulação do capital numa escala global.

Durante a seca de 1970, a SUDENE começou a apresentar sinais de enfraquecimento político; e, por conseguinte, econômico. Nesse contexto, emergiram novos instrumentos da política pública, como o sistema de crédito rural, o fortalecimento do cooperativismo, a assistência técnica e extensão rural, frentes de emergência, políticas de fomento e de condicionamento da produção, o Programa de Integração Nacional (PIN), o Programa de Distribuição de Terra (PROTERRA), o POLONORDESTE e o Projeto Sertanejo, dentre outros.

Todos esses instrumentos da política pública foram bastante eficientes na condução de um projeto modernizador do campo, promovendo de um lado, uma diferenciação no âmbito dos produtores, que ao serem contemplados com tais políticas, diferenciaram-se no contexto espacial; e do outro, promovendo ainda mais o empobrecimento de parte dos produtores. Aqueles que ingressaram nos projetos referidos anteriormente transformaramse em devedores do sistema de crédito. Já os expropriados, tornaram-se boias frias nas grandes propriedades, cujos proprietários, ao serem subsidiados pelo Estado, modernizaram seus empreendimentos, passando a constituir a chamada burguesia agrária. 
Essa realidade pode ser exemplificada com os pequenos produtores que enveredaram em diversos projetos, como: os projetos de colonização criados pelo DNOCS, desenvolvidos no entorno dos açudes públicos, a exemplo do projeto de irrigação no açude de Cruzeta/RN, ou mesmo produtores que ingressaram no Projeto Sertanejo e no POLONORDESTE, dentre outros.

No contexto das políticas públicas implementadas, vale ainda destacar o fortalecimento do cooperativismo incentivado desde os anos de 1970, quando a agricultura brasileira foi submetida a fortes processos de modernização no processo produtivo. O cooperativismo seria a forma pela qual a mentalidade empresarial substituiria a mentalidade "précapitalista" dos produtores rurais (camponeses).

Desse modo, a divulgação e o incentivo ao cooperativismo foram necessários para viabilizar uma estrutura de organização da produção, possibilitando os propósitos modernizantes do planejamento, tais como a assistência técnica e a extensão rural, que funcionaram como instrumentos de implantação de políticas agrícolas, aplicadas sob a forma de pacotes tecnológicos específicos para cada área e cada tipo de produtor.

Em 1971, foi aprovada a lei no 5.764, concedendo vantagens econômicas às cooperativas por meio do Banco Nacional de Crédito Cooperativo, criado em 1951, para estimular e apoiar as cooperativas, mediante financiamento. Essas cooperativas passaram a funcionar na região Nordeste como empresas, orientando-se pelas leis de mercado, sujeitando-se à formação dos preços, e pagando aos associados preços não compatíveis com o valor dos produtos. Na realidade, o cooperativismo se tornou um instrumento político, com vista a evitar o choque frontal entre classes, mascarando assim a luta de classes sob o véu da defesa dos mesmos objetivos.

Ainda associada à política de industrialização podem ser destacadas as seguintes políticas: o Programa de redistribuição de Terras no Nordeste (PROTERRA) e o POLONORDESTE.

O POLONORDESTE tinha por objetivo maior promover o desenvolvimento e a modernização das áreas prioritárias, transformando progressivamente a agropecuária tradicional do Nordeste em economia moderna, voltada totalmente para o mercado. Neste sentido, foram criados alguns polos rurais de desenvolvimento, espalhados estrategicamente pelo território 
regional, de maneira que, nesses núcleos nos quais a organização da produção era mais pura em termos capitalistas, os problemas de fluxo migratório e o fornecimento de alimentos para os centros urbanos seriam resolvidos sem que fosse realizada uma reestruturação.

A realidade de atuação do POLONORDESTE o consagrou como um forte mecanismo de modernização da estrutura produtiva em suas áreas de ação, tanto em nível da produção quanto ao aumento da produtividade. No entanto, suas ações foram concentradas na preparação dos centros urbanos locais, de modo que esses pudessem absorver o excedente de mão de obra que migrava para as cidades, já que o campo se tecnificava. Assim, esse programa procurou modernizar pequenos negócios urbanos, transformando-os em pequenas empresas, as quais deveriam empregar parte da mão de obra.

Diante dos seus objetivos e das ações implementadas, o POLONORDESTE se destacou também pelas contradições por ele geradas, quais sejam: ao mesmo tempo em que procurava facilitar o acesso à terra, a valorização que se dava por meio da construção de infraestrutura elevava o seu preço, dificultando o acesso dos trabalhadores rurais pobres a essa mesma terra.

Dada a sua dimensão, os mais beneficiados foram os grandes proprietários e comerciantes urbanos, pois a modernização, ao contrário do que fora propalado, gerou uma grande quantidade de população desempregada, paralela a um aumento de demanda por terra, garantindo assim a sobrevivência da estrutura tradicional, já que a renda da terra aumentava.

Outro instrumento da política pública para o Nordeste com objetivo de solucionar a problemática regional foi o Projeto Sertanejo, criado em 1976, que tinham como objetivos centrais aumentar a resistência dos estabelecimentos agrícolas contra os efeitos das secas e incentivar a produção agrícola e a bovinização.

O Projeto Sertanejo assumiu importância diferente das frentes de emergência por ser um criador de patrões e de assalariados. Para tal, recorreu aos instrumentos já conhecidos pela sociedade, como: construção de barragens e açudes, preparação de infraestrutura para irrigação e cooperativismo. 
É importante destacar o discurso do acesso à terra por meio da renúncia dos grandes proprietários, de parte de suas terras que quisessem fazer parte do projeto em benefício dos sem terra, articulado no âmbito do Projeto Sertanejo. Na realidade, esse era um instrumento populista e demagógico, uma vez que havia a possibilidade da divisão da propriedade por parte do latifundiário em parcelas inferiores a 500 ha, de modo que driblava a norma, e beneficiava-se.

Por fim, era a política de industrialização, entendida como a grande saída para toda a problemática nordestina que se refletia nas estatísticas que apontavam o avanço da indústria no centro; e, por conseguinte, a menor participação do NE em diversos setores de exportação, resultado de um o crescimento econômico nordestino insignificante, ficando muito inferior ao da região do Centro-Sul. Associado a esse elemento, a alta concentração de renda se apresentava como outro componente adverso, demonstrando a ausência de um mercado de consumo, já que prevalecia uma economia de subsistência.

A política de industrialização teria que intensificar os investimentos industriais, visando a criar, no Nordeste, um centro autônomo de expansão manufatureira. Para tal, seriam utilizadas matérias primas regionais, a fim de tornar as indústrias competitivas como as do Centro-Sul, tanto no mercado regional quanto no mercado nacional, associadas ao aproveitamento do fator regional, a mão de obra barata.

Assim, a modernização da indústria tradicional, sobretudo, a têxtil, seria uma das metas a ser atingida por essa política que passou a ser operacionalizada a partir da criação dos distritos industriais, que apresentavam as melhores e mais modernas condições de infraestrutura existentes. São exemplos dessa realidade: O Centro Industrial de Aratu; o Pólo Petroquímico de Camaçari, na Bahia (BA); O Distrito Industrial de Natal, no RN; o Distrito Industrial de Jaboatão, em PE; e tantos outros, localizados nas demais capitais nordestinas.

A política industrial pensada para o Nordeste brasileiro se baseou em diferentes mecanismos, dentre os quais, os incentivos fiscais, especialmente, o 34/18, bem como os incentivos financeiros, que propiciaram um expressivo movimento de inversões industriais, proporcionado pelo baixo custo do capital. Em outros termos, as pessoas jurídicas poderiam deixar de pagar ao Tesouro Nacional até $50 \%$ do montante de seus impostos. 
Assim, o processo de industrialização que ocorreu no Nordeste, motivado pela intervenção do Estado, provocou um impacto significativo sobre os serviços urbanos, além de promover demandas de infraestruturas especializadas, com rebatimentos de grande magnitude no território das cidades. Ressaltamos as mudanças que ocorreram no contexto de alguns serviços, como: saúde, educação, energia e transportes, dando origem à formação do capital fixo no setor público.

A política de industrialização dinamizou a região Nordeste, de modo que, no global, nas décadas de 1960, 1970 e 1980, ela apresentou a mais elevada taxa média de crescimento do Produto Interno Bruto (PIB) do país; e de 1960 a 1988, a economia nordestina superou a taxa de crescimento média do país em 10\%. Já nos anos de 1970, houve um expressivo investimento público no Nordeste, além da presença da Petrobras, da Companhia Vale do Rio Doce e do Complexo de Carajás, no Estado do Maranhão. Segundo IBGE, em 2010, a participação do Nordeste no PIB brasileiro era da ordem de 13,5\%.

Nos anos de 1990, foi sistematizada uma política pública na esfera federal, expressa pelos programas estruturantes "Brasil em Ação" e "Avança Brasil", que privilegiaram um ordenamento territorial a partir de eixos nacionais de integração e de desenvolvimento, divididos em quatro grandes setores: Desenvolvimento Social (Programa Brasil Mais Justo); Infraestrutura Econômica (Brasil Mais Forte); Informação e Conhecimento (Brasil Mais Competitivo); e Meio Ambiente (Brasil Preservado).

A leitura dessa política esclarece que os maiores beneficiados foram os projetos de grandes investimentos; a visão articulada do planejamento regional foi totalmente descartada; as regiões com maior potencial foram reforçadas, não tendo sido criado qualquer estímulo que potencializasse a integração competitiva.

A escolha do ordenamento do território via eixos de desenvolvimento revela uma pretensão de melhorar as condições sistêmicas dos centros já dinâmicos. No Nordeste, foram contempladas as áreas de produção voltadas para os mercados internacionais, bem como as áreas turísticas, em especial, as litorâneas, uma vez que o turismo de sol e praia passou a ser um setor importante na geração de divisas, ao se transformar em uma atividade de atração de consumo internacional. Para viabilizar esse turismo foi criado o Programa de 
Desenvolvimento do Turismo no Nordeste (PRODETUR/NE), cuja atuação ocorreu em quase todo o litoral nordestino.

Em 2007, foi lançado o Programa de Aceleração de Crescimento (PAC-1); e em 2011, ocorreu o lançamento do PAC-2. Trata-se de uma política pública que propõe um crescimento econômico associado à melhoria das condições sociais, expressa num programa de governo, que coloca como prioridades: investimento em infraestrutura; melhoria do ambiente de investimento; medidas fiscais de longo prazo; desoneração e aperfeiçoamento do sistema tributário; estímulo ao crédito e ao financiamento.

O PAC tem como objetivos: aumentar o investimento em infraestrutura para eliminar os principais gargalos que podem restringir o crescimento da economia; reduzir custos e aumentar a produtividade das empresas; estimular o aumento do investimento privado; e reduzir as desigualdades.

No contexto desse programa, é importante ressaltar que já foram realizados inúmeros investimentos. No caso específico do Nordeste brasileiro, merecem destaque os incentivos feitos na área de educação, como a expansão dos Institutos Federais; a ampliação, expansão e reestruturação das Universidades Públicas Federais, por meio do Projeto de Reestruturação e Expansão das Universidades Federais (REUNI); e, principalmente, a implementação de uma política social, marcada pela presença do programa Bolsa Família, sendo este um programa de redistribuição de renda para as populações carentes.

Não podemos negar que têm sido expressivas as mudanças efetivadas no contexto do território nordestino após a instalação do PAC. Os investimentos em infraestrutura, em especial, aqueles voltados para a construção e melhorias/modernização das rodovias são marcantes. A infraestrutura no setor da educação, bem como a expansão dos ensinos técnico e universitário tem promovido mudanças espaciais de grande magnitude, principalmente, nos espaços urbanos. De 2000 a 2010, a variação do crescimento de matrículas no ensino superior foi de $175,90 \%$, sendo considerado o mais elevado no quadro das regiões brasileiras.

Nas cidades contempladas com essa expansão do ensino universitário, é perceptível a dinâmica do comércio e dos serviços, atreladas a mudanças de práticas sociais, sendo as 
práticas de consumo as que mais chamam a atenção, graças à modernização da atividade comercial.

Outra política que merece relevo é a política social. Essa política tem apresentado rebatimentos importantes no território, em especial, das pequenas cidades, algo que pode ser visualizado na dinâmica destas cidades, no que diz respeito ao comércio e aos serviços. Porém, apesar de ser uma política importante para a melhoria das condições de vida da população, não é possível visualizar um desenvolvimento socioespacial que contemple as diversas dimensões de reprodução do ser humano e do cidadão com um todo: saúde, lazer, trabalho, educação, dentre outros aspectos.

O atendimento à saúde ainda é muito precário, não do ponto de vista técnico em si mesmo, mas do ponto de vista do alcance da assistência. Essa realidade, em parte, expressa a forma concentrada que as políticas de infraestrura assumiram, sobrecarregando os equipamentos de saúde das cidades grandes e médias, ficando uma grande quantidade de cidades sem condições de prestar qualquer serviço à população que busca, em outras cidades, serviços de maior complexidade para o atendimento de suas necessidades. Realidade semelhante acontece quando está em pauta a dimensão do trabalho, do lazer, e outras dimensões da sociedade.

O quadro delineado e explorado a partir das políticas públicas nos conduz a inferir que a reprodução da sociedade, no âmbito da região Nordeste, fomentada e motivada pelas políticas públicas, ainda que tenha favorecido uma dinãmica econômica e social positiva, foi marcada por contradições geradas pelas próprias políticas, que se manifestam por meio da inserção da população no mundo do consumo de mercadorias, ao mesmo tempo em que promoveu a fragmentação do espaço, expressa pela segregação espacial e pela exclusão social, mas também pela formação de enclaves que se reproduzem em consonância ao desenvolvimento técnico científico e informacional, coexistindo com realidades políticas e econômicas que não apenas reproduzem as desigualdades então existentes, mas também reproduzem novas desigualdades, como nos aponta Martins (1997); daí, o surgimento de enclaves. Nesse sentido, destacamos como enclaves econômicos as seguintes áreas:

a) Polo agrícola do sul do Maranhão, onde se desenvolve a produção de soja;

b) área de produção de celulose em Imperatriz, também no estado do Maranhão; 
c) Complexo agroindustrial de Petrolina-PE/Juazeiro/BA, que surgiu nos anos de 1970, graças à política de incentivo à irrigação de frutas tropicais. Nessa área, se destaca a produção de uva voltada não apenas para exportação, mas também para a produção de vinhos. É importante salientar que a produção de uva no Nordeste se constituía até então como algo impossivel, dadas as condições climáticas da região;

d) oeste baiano, onde também se destaca aprodução de soja. Trata-se de uma área de condições morfoclimática do cerrado, onde a soja encontrou condições favoráveis, as quais, associadas à tecnologia, garante destaque para esse espaço na produção de soja em nível nacional;

e) Vale do Açu, no RN. Nessa área, o destaque é para a produção de frutas tropicais destinadas aos mercados europeu e americano, sendo o melão e a banana os principais produtos. A irrigação sempre foi vista como a principal saída para o estado de pobreza do Nordeste brasileiro. Porém, em nossa compreensão, o resultado das políticas voltadas para a produção de tais espaços foi a formação de verdadeiras ilhas de prosperidade, as quais têm uma produção voltada totalmente para o mercado externo, produzindo frutas tropicais com o uso de alta tecnologia, empregando a força de trabalho assalariada, em especial, temporária ou mesmo diarista, que, expropriada, não lhe restou outra alternativa;

f) áreas de desenvolvimento turístico. Nestes locais, o destaque é para os grandes resorts, os quais se cosntituem espaços localizados em grandes áreas do litoral nordestino, sendo a maioria deles de capital internacional, como é o caso da rede de resort Vila Galé. Trata-se de uma rede de capital português, que se faz presente nos estados de Pernambuco, Bahia, Ceará; e, em 2017, dará início à construçao de um resort na praia de Touros, no RN.

Em todas essas áreas, os processos tecnológicos desenvolvidos são de alta complexidade, o que permite uma elevada produtividade e garantia de inserção nos mercados nacional e internacional. No entanto, paralelo a essa realidade avançada tecnologicamente, reproduzse uma sociedade marcada pela pobreza; e, portanto pelas desigualdades sociais. Um bom exemplo dessa realidade é o vale do Açu, onde podem ser encontrados os mais baixos índices de desenvolvimento humano do RN, daí porque entendemos serem essas áreas, enclaves econômicos que se reproduzem articulados aos espaços de pobreza e de 
desigualdade social. A baixa renda mensal considerada pelo IBGE nos estudos da distribuição da População Economicamente Ativa- PEA das pessoas com mais de 10 anos é um indicador importantre da pobreza e das desigualdades. De acordo com os dados do Censo Demográfico do IBGE, em 2010, no conjunto do Nordeste brasileiro, 52,6\% ganhavam até 2 salários mínimos. Essa realidade se soma aos elevados índices de analfabetismo, que embora tenha diminuído desde o ano 2000, quando era de 24,6\%; ainda é bastante elevada, apresentando o índice de $17,6 \%$ em 2010 , sendo a região de mais elevado número percentual de analfabetos.

\section{Para não concluir}

O título dado a este tópico se justifica pelo entendimento de que, embora o debate tenha raízes num passado distante, ainda é atual, frente aos novos processos que se desencadeiam; e por isso, o resgate por meio do qual algumas inferências se apresentam de forma compulsória; e, portanto, não podem deixar de ser explicitadas.

Como foi referenciado no texto, o Brasil, e particularmente, o Nordeste, vive um momento de expressiva mudança em sua base social e econômica na atualidade, ainda que esteja ocorrendo uma crise, que sem sombra de dúvida, possui um caráter mais político que econômico.

Assistimos, ao longo da história de intervenção do Estado, a uma superposição de políticas públicas, as quais pouco dialogavam entre si. Na tentativa de construção de outro cenário, o governo Lula (2003-2011) lançou o Programa Fome Zero, cujo objetivo maior era trabalhar com uma política que funcionasse como carro chefe na condução de soluções dos problemas que historicamente assolavam a realidade brasileira. O Estado assumiu então o papel de locomotiva da transformação acelerada da sociedade local, sendo também responsável pela incorporação de setores sociais "arcaicos" na moderna economia de mercado.

O resultado da política desenvolvida pelo Programa Fome Zero, associada ao PAC, foi a emergência de um conjunto de mudanças de conteúdo social, como o aumento da 
expansão do ensino técnico, expansão do ensino universitário, maior acesso da população aos bens de consumo, graças à política social, e também econômico; daí o aumento da participação do nordeste no PIB nacional, além de passar a atrair alguns investimentos.

No entanto, o Nordeste brasileiro continua sendo uma das regiões de maior desigualdade social e de maior número de pobres. Essa afirmação se sustenta na associação histórica da estrutura de poder local a uma estrutura de poder centralizado. Desse modo, as duas teses clássicas que procuraram explicar essa estrutura de poder: a localista, defendida por Gilberto Freyre e por Maria Isaura Queiroz; e a centralista, defendida por Raimundo Faoro se complementam, e portanto, não se apresentam como antagônicas.

Diante dessa realidade, inferimos que os resultados das políticas públicas voltadas para a promoção do desenvolvimento, sempre se constituíram em vetores importantes para duas realidades espaciais distintas: os espaços nos quais o capital se reproduz de forma ampliada, em bases estruturais modernas; espaços estes aos quais denominamos enclaves; e os espaços economicamente e socialmente atrasados.

Assim, a distribuição de investimentos públicos ocorreu de forma diferenciada, selecionando os espaços marcados por condições favoráveis ao crescimento das economias com maiores e melhores condições de reprodução da sociedade capitalista.

Portanto, as políticas públicas, em especial, aquelas voltadas para a produção de infraestrutura, assim como as de conteúdo econômico e tecnológico, produziram também e de forma acentuada, as desigualdades socioespaciais, a exclusão social e a segregação; ou seja, proporcionaram a coexistência de espaços opacos e espaços luminosos, conforme a ideia de Santos (2006).

Além desse aspecto, os dados apresentados e a leitura que podemos fazer por meio de incursões empíricas no território, evidenciam também que, no plano geral, as políticas públicas no Brasil, em especial, as de base territorial e econômica, promoveram a inserção do Brasil no processo de reprodução do capital, subordinada à globalização financeira e comercial, com a destruição de setores e regiões inteiras, garantindo a abertura cada vez maior do mercado brasileiro ao capital internacional, fato esse que também é responsavel pelas desigualdades socioespaciais. 
O resultado dessa opção foi o abandono das áreas consideradas periféricas, frente ao desenvolvimento industrial, conjugando desintegração, carência e depressão econômica, de tal modo que faz sentido a afirmação de que a atuação das políticas públicas implementadas no Nordeste brasileiro ocorre em duas frentes, produzindo e reproduzindo a diversidade regional, a qual, para Araújo (2008), "é um patrimônio brasileiro que fará a diferença no século XXI".

Por fim, inferimos que como resultante desse processo desigual, ainda prevalece uma expressiva desvantagem do Nordeste em relação à região Sudeste, quando se trata de investimentos a serem efetuados no contexto territorial brasileiro. O Nordeste ainda é pouco competitivo nesse sentido, de modo que a atração de empreendimentos produtivos ocorre em um contexto de seletividade espacial bem demarcado no âmbito da política pública, o que muito contribuiu para as grandes diferenças regionais também.

\section{Referências}

ANDRADE, Manoel Correia de. A terra e o homem no Nordeste, São Paulo: Brasiliense, 1963. 336 p.

ANDRADE, Manoel Correia de . Poder Político e Produção do espaço. Recife: Massangana, 1984. 129p.

Andrade, Ilza Araújo Leão de. Política urbana e poder local em cidades do Nordeste. Vivência. 1996 v. 10 , n.1/2, p. 117-128.

ARAÚJO, Tânia Bacelar de. Ensaios sobre o desenvolvimento brasileiro: heranças e urgências. Rio de Janeiro: Revan,fase, 2000.

ARAÚJO, Tânia Bacelar de.A diversidade regional é um dos patrimônios brasileiros que farão diferença no século XXI.Revista de informações e debates do IPEA. Maio de 2008, ed. 45ạ.

CASTRO, Iná Elias de. O mito da necessidade: discurso e prática do regionalismo nordestino. Rio de Janeiro: Bertrand Brasil, 1992. 247 p.

COSTA, Ademir Araújo da. Tecnologia e desemprego: o caso da região salineira de Macau - RN. Natal: UFRN, CCHLA, 1993. 142p.

COHN, Amélia. Crise regional e planejamento: o processo de criação da SUDENE. São Paulo: Perspectiva, 1976. 165 p. (Coleção Debates).

GOMES, Gustavo Maia. Ideias para a modernização do Nordeste. In: VELOSO, João Paulo dos Reis. (org.) Brasil em mudança: Fórum Nacional. São Paulo, Nobel, 1991. p. 235- 250.

GOMES, Gustavo Maia. Velhas secas em novos sertões: continuidade e mudanças na economia do semiárido e dos cerrados nordestinos. Brasília: IPEA, 2001.

GOMES, Rita de Cássia da Conceição; FELIPE, José Lacerda Alves. Rio Grande do Norte e outras Geografias. Natal - RN: UFRN, CCHLA, 1994. (Coleção Humanas Letras) (Coleção mossoroense). 
INDOVINA, Francesco; CALABI, Donatella. Sobre o uso capitalista do território. Orientação. 1992, no 9, p. 3766.

LEAL, Victor Nunes. Coronelismo, enxada e voto. 5a ed. São Paulo: Alfa-Omega, 1975.

MARTINS, José de Souza. Exclusão social e a nova desigualdade. 4a ed. São Paulo: Paulus, 2009.

OLIVEIRA, Francisco de. Elegia para uma re(li)gião: SUDENE, Nordeste, planejamento e conflito de classes. 3.ed. Rio de Janeiro: Paz e Terra, 1981. 132 p. (Estudos sobre o Nordeste, v. 1).

POCHMANN, Márcio; AMORIM, Ricardo. Atlas da exclusão social no Brasil. 1ạ ed. São Paulo: Cortez, 2003.

PONTES, Beatriz Maria Soares. Estado brasileiro: território natureza e sociedade em conflito. In PONTES, Beatriz Maria Soares. Estado e planejamento urbano: "na prática a teoria é outra". Natal: UFRN, 1994. Coleção Humanas Letras.)

Rolnik, Raquel. Planejamento urbano nos anos 90: novas perspectivas para velhos temas. In RIBEIRO, Luiz César de Queiroz; JÚNIOR, Orlando Alves dos Santos. Globalização, fragmentação e reforma urbana: o futuro das cidades brasileiras na crise. Rio de Janeiro: Civilização Brasileira, 1994. p. 351-360.

SALES, Tereza. Raízes da desigualdade social na cultura política brasileira. Revista brasileira de ciências sociais. 1994, no 25, p. 26-27.

SANTOS, Milton. A Natureza do Espaço: Técnica e Tempo, Razão e Emoção. 4a ed. São Paulo: Editora da Universidade de São Paulo, 2006. 